\title{
Finite Element Modeling in Friction Stir Welding of Two Dissimilar Pipes
}

\author{
Ahmed Ali Akber, Ali Abbar Khleif, Abbas Nasser Hasein
}

\begin{abstract}
The Finite Element Modeling has been achieved for two dissimilar pipes welded by friction stir welding for given operating conditions and cases. Moreover, this analysis has been carried out to find the effect of hydrostatic pressure test on the welding area of the pipe by ANSYS Workbench software. In this study dissimilar materials of different pipes were used for FSW, which they were joined as 6063 aluminum alloy pipe with 6082 aluminum alloy pipe and C36000 high-leaded brass pipe with C12200 copper alloy pipe. In this study six parameters were used and with those parameters, eight (8) cases were welded and examined with hydrostatic tests and tensile test. The process was accomplished by varying one of the parameters (rotation speed) and keeping the others as constants.
\end{abstract}

Keywords: ANSYS Workbench software, dissimilar pipes, Finite Element Modeling, hydrostatic pressure.

\section{INTRODUCTION}

Finite element modeling is a numerical technique used to resolve the mathematical physics and engineering problems. The usual importance of domain problems in mathematical physics and engineering that are resolvable with using the finite element modeling (mothed) involve fluid flow, mass transport, electromagnetic potential, heat transfer, and structural analysis. It is usually not possible to get solutions of analytical mathematics with regard to problems including complex material properties, geometries, and loadings. The solutions of the analysis are those given by a mathematical expression that yields the rates of the wanted unidentified amounts at every site in the figure and therefore effective for an infinite number of sites in the figure. Due to the complex material properties, loadings and geometries are not generally available; these analytical solutions usually need the equations of partial differential or the regular solution. Friction stir welding (FSW) is a relatively new welding process that may have significant advantages compared to the fusion processes. This metal jointing technique is derived from the conventional friction welding. $[1,2,3]$ Finite Element modeling is widely applied in

Revised Manuscript Received on March 16, 2020.

* Correspondence Author

Ahmed Ali Akber*, department of Production Engineering and Metallurgy, University of Technology, akbarthree@yahoo.com

Ali Abbar Khleif, department of Production Engineering and Metallurgy, University of Technology, aliuot@yahoo.com

Abbas Nasser Hasein, department of Mechanical Technology/ Production, Kut Technical Institute, Middle Technical University, abbas133eng.an@gmail.com

(C) The Authors. Published by Blue Eyes Intelligence Engineering and Sciences Publication (BEIESP). This is an open access article under the CC BY-NC-ND license (http://creativecommons.org/licenses/by-nc-nd/4.0/) investigating most of the scientific phenomena. This field in friction stir welding was took researchers attention. Bahman Meyghani, et al. (2017) [4] were a team of those who tried to investigate of the friction stir welding 3D nature that makes the trial very difficult. Furthermore, trial notes are consuming of time and frequently costly, and regularly there is measuring inexactness in the data through trial tests. Hence, they have employed a Finite Element Methods to beat the difficulty, for decrease the costs and for rise the accuracy. It must be observed that, because of the great distortions attendance of the metal through friction stir welding process, high distortions of net may occur in the simulation of numerical. In their investigation and between various numerical techniques a comparison done for friction stir welding thermal analysis for both global and local scales is studied and the uses of every technique in the friction stir welding method was discussed in detail. A.Rajasekar, T.Prabhu. (2015) [5]: They aim to analysis FSW of the AL2024 with AL6063 by FEM. They were performed passing (TFEA) to get the distributed temperature in the joint through the welding process. As a FEM the heat input from the tool shoulder and the tool pin were considered. Moreover, they were used a movable heat supply with a temperature apportionment simulating the temperature produced from the rubbing between the shoulder of tool and the work piece in the heat transmission analysis. 3D models they were accomplish with HyperMesh software. They detected that the higher heat close the weld rises as the holding time of the tool and rotational speed were incremented. The heat is reduced as the tool crosswise speed rises. Furthermore, they were concluding that apply of a movable heat supply method proved a dependable technique to simulate friction stir processing. A 3D model was applied by C.M. Chen, R. Kovacevic, (2003) [6] to investigate depending on FEA which was used to survey thermomechanical method and the history of the heat in the butt welding of AL6061-T6. The model combines the tool mechanical response and thermo-mechanical method of the welded metal. The heat source combined in the model consists of base metal friction with the pin and the shoulder. So as to offer a quantifiable frame to comprehension the mechanism of the FSW thermo-mechanical method, in the FSW the history of the heat and the development of longitudinal, lateral, and through-thickness stress were simulated numerically. XRD method was used to calculate the welded plate remaining stress, and using the calculated results to confirm the suggested model efficiency.

Published By:

Blue Eyes Intelligence Engineering

\& Sciences Publication

(C) Copyright: All rights reserved.

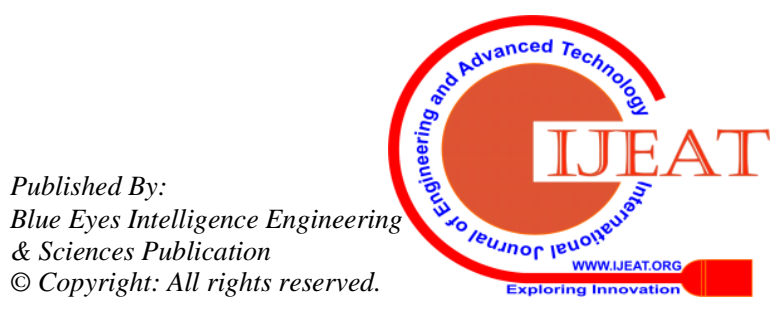

DOI: 10.35940/ijeat D6651.049420

Journal Website: www.ijeat.org 
They were offered the connection between the method parameters and the measured remaining stresses of the weld. It was expected that the model may be prolonged to improve the friction stir welding method to reduce the remaining stress of the weld. Also thermo-mechanical numerical simulations and a 3D nonlinear thermal was made for 304L stainless steel FSW by X.K. Zhu, Y.J. Chao. (2003) [7]. A finite element analysis code-WELDSIM, was developed precisely for weld simulation. Two joining experiments with different speeds of rotation $300 \mathrm{rpm}$ and $500 \mathrm{rpm}$ were carried out. Their aim was to investigated in the difference of passing temperature and remaining stress in FSW 304L stainless steel plate. They have depended on the investigational registers of passing temperature at a number of precise sites through the FSW method for the 304L stainless steel, and they developed an opposite analysis technique for thermal numerical simulation. When they were calculating the passing temperature field, then they determining the remaining stresses in the welded plate using 3D elastic-plastic thermo-mechanical simulation. They also studied the influence of fitting relief afterward the welding on the remaining stresses. Moreover, they measured the evaluation with the remaining stress areas using the neutron diffraction method, and this indicated that the results from the current numerical simulation have perfect treaty with the experiment information.

\section{EXPERIMENTAL WORK}

\section{A. Friction Stir Welding Process Materials Used}

All pipes that used in the study were the same dimensions, the wall thickness $(5 \mathrm{~mm})$ and the outside diameter of the pipes was (89 mm) as shown in Fig. (1) and these pipes welded on a traditional universal milling machine was used to perform FSW process type "HECKERT" made in "German". Mechanical properties of all pipes materials used are given in Table (1). Furthermore, Table (2) shows AL6063, AL6082 and C12200 copper alloy and C36000 high-leaded brass chemical composition.

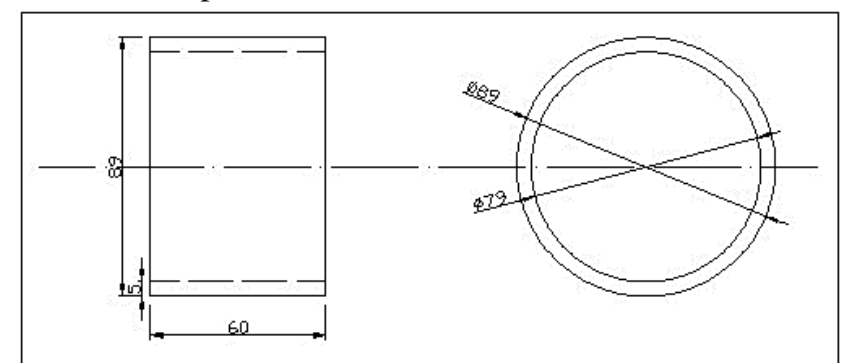

Fig. 1. Size and Dimensions of the Pipes that Used in the Study (all dimensions in $\mathbf{~ m m}$ )

Table- I. Mechanical Properties of the Materials used in the Process

\begin{tabular}{|c|c|c|c|c|c|c|c|c|c|}
\hline \multirow[b]{2}{*}{ 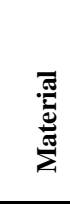 } & \multicolumn{9}{|c|}{ Composition, wt. \% } \\
\hline & Si & $\mathbf{F e}$ & $\begin{array}{l}\mathbf{C} \\
\mathbf{u}\end{array}$ & Mn & Mg & $\begin{array}{l}\mathbf{C} \\
\mathbf{r}\end{array}$ & $\begin{array}{l}\mathrm{Z} \\
\mathrm{n}\end{array}$ & AL & $\begin{array}{c}\text { Speci } \\
\text { fied } \\
\text { other } \\
\text { eleme } \\
\text { nts }\end{array}$ \\
\hline $\begin{array}{c}\mathrm{AL} \\
6063\end{array}$ & $\begin{array}{c}0.20- \\
0.6\end{array}$ & $\begin{array}{c}0 . \\
35\end{array}$ & $\begin{array}{c}0 . \\
1\end{array}$ & 0.1 & $\begin{array}{c}0.45- \\
0.9\end{array}$ & $\begin{array}{c}0 . \\
1\end{array}$ & $\begin{array}{c}0 . \\
1\end{array}$ & $\begin{array}{l}\text { Re } \\
\mathrm{m} .\end{array}$ & $\begin{array}{c}0.10 \\
\mathrm{Ti}\end{array}$ \\
\hline
\end{tabular}

\begin{tabular}{|c|c|c|c|c|c|c|c|c|c|}
$\mathrm{AL}$ & & & & & & & & & \\
6082 & $0.7-1$ & 0. & 0. & $0.10-$ & $0.6-1$ & 0. & 0. & $\mathrm{Re}$ & 0.10 \\
$\mathrm{C}$ & 5 & 1 & 0.40 & .2 & 25 & 2 & $\mathrm{~m}$. & $\mathrm{Ti}$ \\
\hline $\mathrm{C} 12$ & & & 99 & & & & & & \\
200 & --- & --- & .9 & --- & --- & --- & --- & --- & $0.02 \mathrm{P}$ \\
\hline & & & 60 & & & & & & \\
& & 0. & .0 & & & & & & \\
& & 35 & - & & & & & & $2.5-$ \\
$\mathrm{C} 36$ & & $\mathrm{~m}$ & 63 & & & & $\mathrm{~B}$ & & $2.7 \mathrm{~Pb}$ \\
000 & --- & $\mathrm{ax}$ & .0 & --- & --- & --- & al. & --- & 3.7 \\
\hline
\end{tabular}

Table- II. Chemical Composition of AL 6063 alloy, AL 6082 alloy, C12200 copper alloy and C36000 high-leaded brass

\begin{tabular}{|c|c|c|c|c|c|c|}
\hline \multirow{2}{*}{ Material } & \multicolumn{2}{|c|}{$\begin{array}{c}\text { Tensile } \\
\text { Strength }\end{array}$} & \multicolumn{2}{c|}{$\begin{array}{c}\text { Yield } \\
\text { strength }\end{array}$} & $\begin{array}{c}\text { Elongati } \\
\text { on } \\
\text { \% }\end{array}$ & $\begin{array}{c}\text { Hardness } \\
\text { HB }\end{array}$ \\
\cline { 2 - 5 } & MPa & Ksi & MPa & Ksi & $7.3-21$ & 25 \\
\hline AL 6063 & 90 & 13 & 48 & 7 & $70.3-18$ & 40 \\
\hline AL 6082 & 140 & 20.3 & 85 & 12.3 & $6.3-18$ & 110 \\
\hline AL 7022 & 285 & 41.3 & 245 & 35.5 & 65 & 50 \\
\hline C12200 & 220 & 32 & 69 & 10 & 43 & 135 \\
\hline C36000 & 340 & 49 & 115 & 17 & 53 \\
\hline
\end{tabular}

\section{B. Welding Parameters}

In this study the parameters were used in FSW process described briefly in the table (3).

Table- III. Set of Parameter Were Used in FSW Process

\section{Hydrostatic Test}

Hydrostatic testing of piping is designed for internal pressure, and this test was done in this study for the friction stir welding pipe by the hydrostatic pressure system test in the Kut technical institute.

\section{Finite Element Modeling of FSW Pipes}

By Ansys software version 18.0 the Finite Element Modeling have been done to find out the deformation occurred from the effect of hydrostatic pressure on the Friction stir welding joint area of every two joined pipes of the study.

\section{E. Geometry of Friction Stir Welding Pipes}

The sketch of pipe used here in friction stir welding and shown in Fig. (1) has been built in the Ansys workbench software version 18.0 as illustrated in Fig. (2).

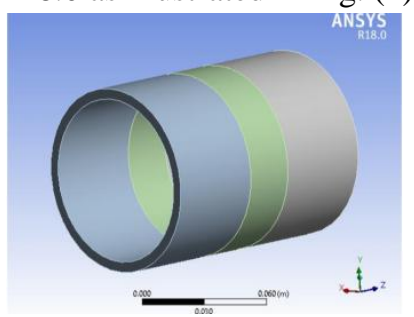

Fig. 2. The pipe geometry built in the Ansys workbench software version 18.0

Published By:

Blue Eyes Intelligence Engineering \& Sciences Publication 


\section{F. Meshing of Friction Stir Welding Pipes}

In this study, the mesh stage is done in Ansys Mechanical interface by double-click on Model cell in the project schematic. After opening Ansys mechanical interface, the mesh of model tree is selected by right click on and Generate Mesh is chosen then the mesh stage is complete with 13454 nodes and 1980 elements, as illustrated in Fig. (3).

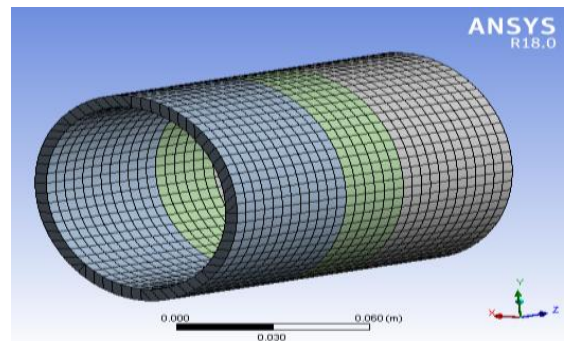

Fig. 3. FSW pipe generated Mesh

\section{G. Analysis of Setting (Setup) of Friction Stir Welding Pipes}

Again by using the FE Modeler system to make the analysis setting of the friction stir welding pipe, the inserting of hydrostatic pressure is done. Right click is used on the analysis setting of the model tree and selecting 'Insert' then selecting Hydrostatic pressure, after that the rest of the boundary conditions of the study is inserted (Standard Earth Gravity in Z Component $-9806.6 \mathrm{~mm} / \mathrm{s}^{2}$, the applied pressure 35 bar, ....etc.). [8]

\section{RESULTS AND DISCUSSIONS}

\section{A. Hydrostatic Test Results of FSW Joints}

Hydrostatic Test was made for selected eight cases of FSW, and the results were as shown in Table (4) below.

Table- IV. The results of hydrostatic test for eight cases of FSW pipes

\begin{tabular}{|c|c|c|l|}
\hline $\begin{array}{c}\text { Case } \\
\text { No. }\end{array}$ & $\begin{array}{c}\text { Joint } \\
\text { Materials }\end{array}$ & $\begin{array}{c}\text { Max. } \\
\text { Pressure } \\
\text { Value in } \\
\text { bar }\end{array}$ & \multicolumn{1}{c|}{ Notes } \\
\hline 17 & AL6063+ AL6082 & 23 & $\begin{array}{l}\text { Leakage at the stir zone at } \\
24 \text { bars. }\end{array}$ \\
\hline 18 & AL6063+ AL6082 & 27 & $\begin{array}{l}\text { Leakage at the stir zone at } \\
28 \text { bars. }\end{array}$ \\
\hline 19 & AL6063+ AL6082 & 30 & \multicolumn{1}{c|}{ No leakage } \\
\hline 20 & AL6063+ AL6082 & 29 & $\begin{array}{l}\text { Leakage at the stir zone at } \\
30 \text { bars. }\end{array}$ \\
\hline 33 & C12200 + C36000 & 26 & $\begin{array}{l}\text { Leakage at the stir zone at } \\
27 \text { bars. }\end{array}$ \\
\hline 34 & C12200+ C36000 & 29 & $\begin{array}{l}\text { Leakage at the stir zone at } \\
30 \text { bars. }\end{array}$ \\
\hline 35 & C12200 + C36000 & 35 & No leakage \\
\hline 36 & C12200 + C36000 & 35 & No leakage \\
\hline
\end{tabular}

From the results above of hydrostatic test for AL6063 to AL6082 welded cases, the best result (No leakage) was when welding conditions were $1300 \mathrm{rpm}$ rotational speed and 1.7 $\mathrm{mm} \backslash \mathrm{min}$ travelling speed (welding speed) while increasing rotational speed of the tool resulted in defected stirred zone due to high heat generation and as a result coarse grained structure formation. Moreover, the best results (No leakage) for C12200 + C36000 were in cases 35 and 36 where the rotational speed is $1300 \mathrm{rpm}$ and $1525 \mathrm{rpm}$ respectively since copper alloy C12200 and brass alloy C36000 require too much heat to be generated at high rotational too speeds for excessive forming and stir mixing.

\section{B. Tensile Test: Load-Deformation Effect of Tensile Test}

The Load-Deformation curves for weld joints (AL6063 \& AL6082 and C12200 \& C36000) are shown in figures below.

\section{Load-Deformation Effect of Tensile Test of AL6063 \& AL6082 FSW Joints:}

FSW joints made at welding conditions of rotational speeds of $775,1000,1300$ and 1525 rpm with a travelling welding speed of $1.7 \mathrm{~mm} \backslash \mathrm{min}$ were tested for tensile strength measuring of welded zone. Figure (4-a) reveals a fracture tensile load of about 6020N (100Mpa) when joints were produced at $775 \mathrm{rpm}$ and those welded at $1000 \mathrm{rpm}$ showed a tensile fracture load of $5780 \mathrm{~N}$ (96Mpa) as shown in Fig. (4-b). In Fig. (4-c) where the joint was friction stir welded at 1300rpm, the fracture tensile load obtained was more than $7090 \mathrm{~N}$ (about 120Mpa) while at $1525 \mathrm{rpm}$ a tensile fracture load of $6450 \mathrm{~N}$ (107Mpa) was observed as indicated in Fig. (4-d).

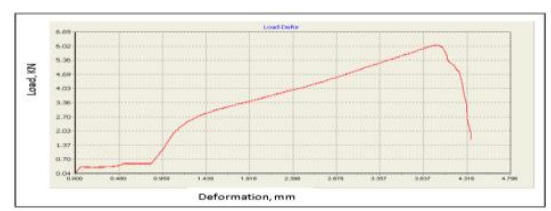

(a)

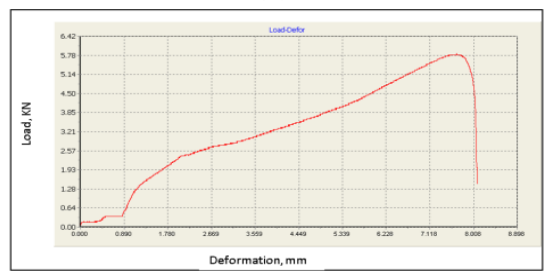

(b)

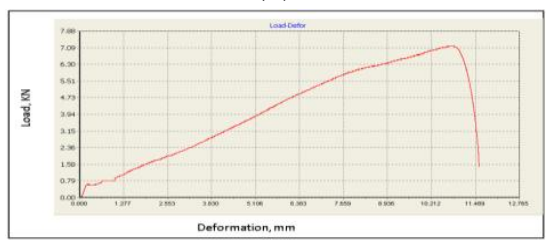

(c)

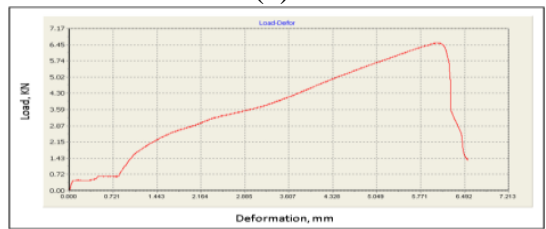

(d)

Fig. 4. Load-Deformation of tensile test curve for FSW weld joints AL6063 \& AL6082 at (a). 775 rpm, (b). 1000 rpm, (c). 1300 rpm, (d). 1525 rpm. 


\section{Finite Element Modeling in Friction Stir Welding of Two Dissimilar Pipes}

From the result of Load-Deformation curves above for FSW joint of AL6063 to AL6082, the best result is when the rotational speed was $1300 \mathrm{rpm}$ where the highest microhardness was achieved due to the fine grained structure of the stirred zone with the formation of intermetallic compounds of MgxSi and AlxMg at FSW temperature, moreover the tensile strength of two aluminum alloys (Al6063 and AL6082) ranges between 90 to 140Mpa that means accepted efficiency of FSW of those couple of pipe alloys was achieved.

\section{Load-Deformation Effect of Tensile Test of C12200 \& C36000 FSW Joints:}

C12200 Copper alloy pipe welded to C36000 high-leaded brass pipe were tested also to determine the tensile strength, the plots in Figs. (5-a), (5-b), (5-c), and (5-d) show that increasing rotational tool speed increases tensile joint strength.

Lowest tensile strength load value of $3680 \mathrm{~N}$ was at $775 \mathrm{rpm}$ and increased by increasing rotational speed to $8920 \mathrm{~N}$ (148.66Mpa) at $1525 \mathrm{rpm}$. The chemical composition of C36000 in table (2) outlines high percentages of lead up to $12.4 \%$ and zinc up to $11.3 \%$ with a $3.6 \%$ Sn. These low melting elements are the main causes of obtaining low strength FSW joints compared to both copper and brass pipes. At low rotating tool speed 775 and $1000 \mathrm{rpm}$ the heat generated is too much compared to high speeds (1300 and $1525 \mathrm{rpm}$ ) where short duration contact of the tool with the base pipe copper alloys so the presence of these low temperature elements $(\mathrm{Pb}, \mathrm{Zn}$ and $\mathrm{Sn})$ resulting in weak layers specially of pure lead or its intermetallic compounds of $\mathrm{CuxPb}$ and CuxZn. In table (1) the tensile strength of copper C12200 and C36000 are 220 and 340 Mpa respectively and at $1525 \mathrm{rpm}$, the highest value was achieved (148.66Mpa) which may be due to no more low temperature layers were agglomerated compared to low rotating speeds.

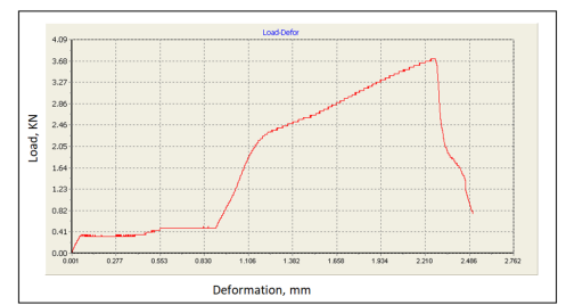

(a)

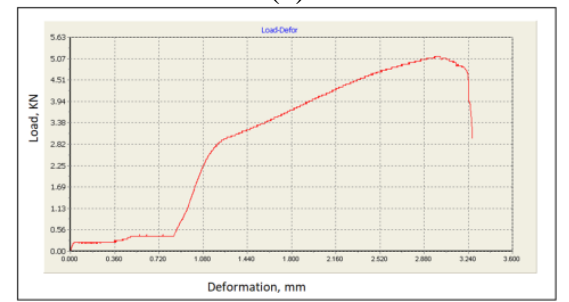

(b)

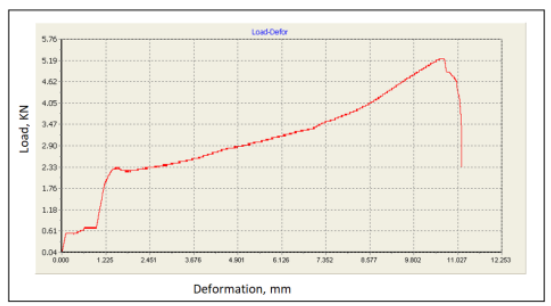

(c)

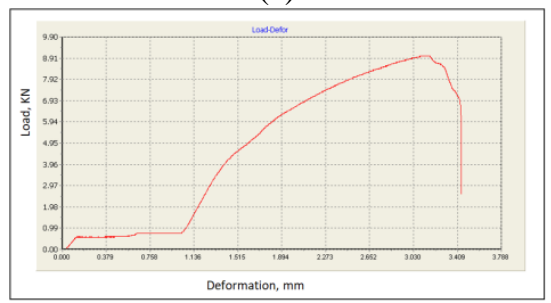

(d)

Fig. 5. Load-Deformation of tensile test curve for FSW C12200 and C36000 weld joints at (a). 775 rpm, (b). 1000 rpm, (c). 1300 rpm, (d). 1525 rpm.

C. The Results and Discussions of FEM for FSW Pipes

1. FEM of The Total Deformation Effect of (AL6063 \& AL6082) weld joints

The total deformation effect of weld joints (AL6063 \& AL6082) are studied by Finite Element Modeling using ANSYS 18.0 before and after friction stir welding as shown in Figs. (6) and (7).

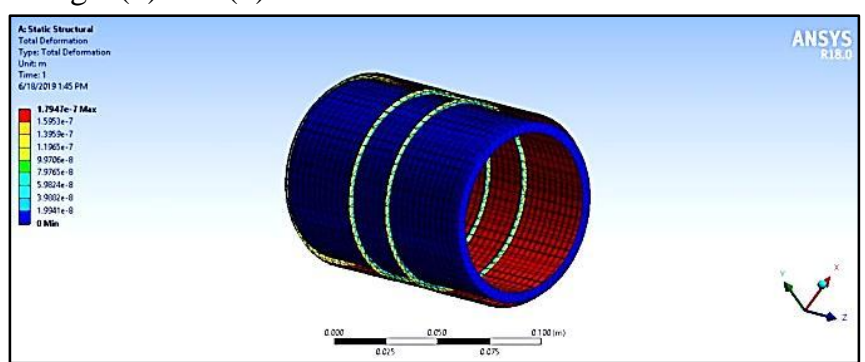

Fig. 6. Total deformation model before FSW of AL6063 and AL6082 joint

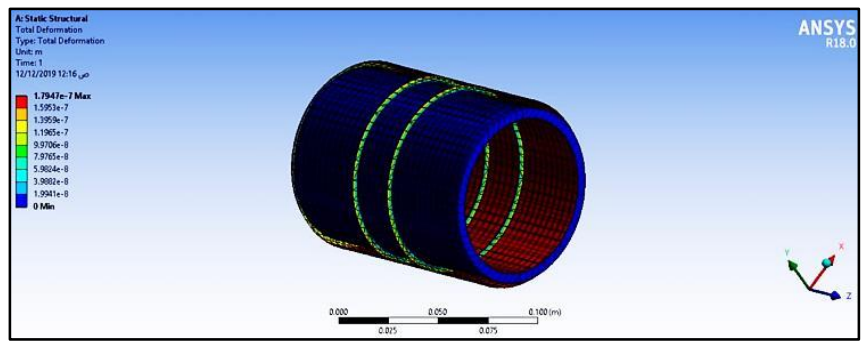

Fig. 7. Total deformation model after FSW of AL6063 and AL6082 joint

The results above of finite element modeling were done by ANSYS 18.0 software which showed that the pipe joint area capable to stand (35 bar) practical pressure before FSW and after FSW (at the process time).

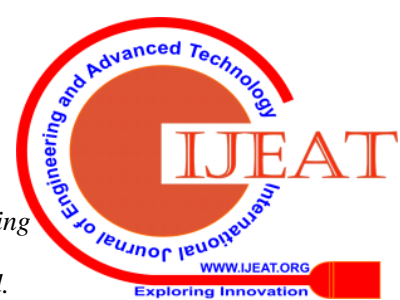




\section{FEM of The Total Deformation Effect of weld joints (C12200 and C36000)}

The total deformation effect of weld joints (C12200 and C36000) are studied by Finite Element Modeling using ANSYS 18.0 before and after friction stir welding as shown in Figs. (8), and (9).

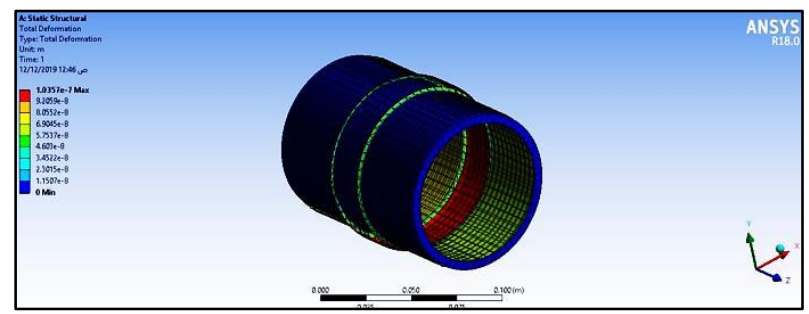

Fig. 8. Total deformation model before FSW of C12200 and C36000 joint

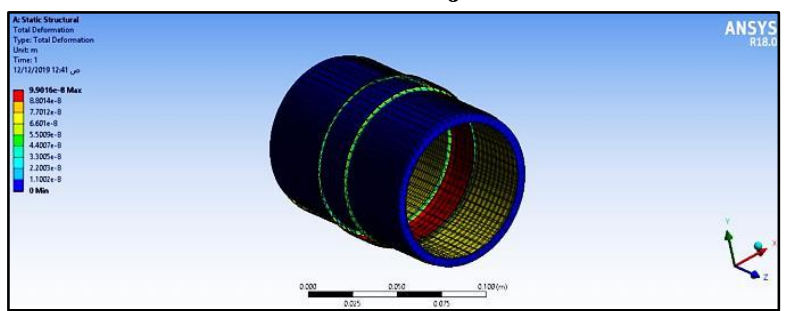

FIGURE 9. Total deformation model after FSW of C12200 and C36000 joint

The results of FEM obtained by ANSYS 18.0 software show that the weld joint area of C12200 and C36000 pipes can bear (35 bar) applied pressure before FSW and after FSW.

\section{CONCLUSION}

From the results of the current study, several conclusions can be drawn:

1. From the results of hydrostatic test for AL6063 with AL6082 weld joints cases, it can be conclude that the good result (No leak) was where the rotational speed is $1300 \mathrm{rpm}$ (case 3).

2. The best results of hydrostatic test (No leak) for C36000 high-leaded brass with C12200 copper alloy weld joints cases are where the rotational speed are $1300 \mathrm{rpm}$ and $1525 \mathrm{rpm}$ respectively (cases 7 and 8).

3. The highest tensile strength load of (7090N) for AL6063 with AL6082 weld joint cases the greatest result is where the rotational speed is $1300 \mathrm{rpm}$ (case 3).

4. The highest tensile strength load of (8920N) for C12200 and C36000 weld joint cases is where the rotational speed is $1525 \mathrm{rpm}$ (case 8).

5. From the analysis results of Ansys software version 18, models established show that the welding joint of AL6063 with AL6082 and C12200 and C36000 pipe are able to withstand pressure more than 35 bar before and during the working time.

\section{REFERENCE}

1. Daryl L. Logan, A First Course in the Finite Element Method, Fourth Edition, University of Wisconsin-Platteville, COPYRIGHT 2007 by Nelson, a division of Thomson Canada Limited, Printed and bound in the United States.
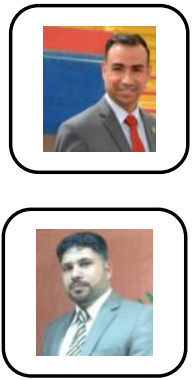
Technology, Baghdad, Iraq

Abbas Nasser Hasein is asst. Lecturer in the departmen of Mechanical Technology/ Production, Kut Technical Institute, Middle Technical University, Waset, Iraq. Production Engineering and Metallurgy, University of Technology, Baghdad, Iraq.

\section{AUTHORS PROFILE}

